\title{
QUALIDADE DA ÁGUA DE NASCENTES COM DIFERENTES USOS DO SOLO NA BACIA HIDROGRÁFICA DO CÓRREGO RICO, SÃO PAULO, BRASIL
}

\author{
NICOLE M. M. DONADIO ${ }^{1}$, JOÃO A. GALBIATTI ${ }^{2}$, RINALDO C. DE PAULA ${ }^{3}$
}

RESUMO: Com o objetivo de verificar a influência de remanescentes de vegetação ciliar e da ação antrópica na qualidade da água, estudaram-se quatro nascentes, sendo duas com a presença de vegetação natural remanescente e duas com predominância de atividades agrícolas. Essas nascentes fazem parte da bacia hidrográfica do Córrego Rico, estando localizadas nos municípios de Taquaritinga e de Guariba - SP, em duas classes de solo: Argissolo e Latossolo, respectivamente. Definiram-se pontos de coleta da água nas nascentes e ao longo dos cursos d'água (entre 0 a $50 \mathrm{~m}$ da nascente), em dois períodos (chuvoso e seco). Foram analisadas as seguintes variáveis: cor, pH, temperatura, turbidez, alcalinidade, dureza total, dureza em magnésio, dureza em cálcio, fósforo, nitrogênio e demanda bioquímica de oxigênio. De maneira geral, ocorreu agrupamento por nascentes e também por períodos, confirmando que os períodos de amostragem, assim como as características e diferentes usos do solo influenciam na qualidade da água das microbacias. As variáveis cor, turbidez, alcalinidade e nitrogênio total foram as que apresentaram maior importância relativa nas variáveis canônicas.

PALAVRAS-CHAVE: microbacia, recursos hídricos, uso do solo.

\section{WATER QUALITY OF SPRINGS WITH DIFFERENT LAND USES IN CÓRREGO RICO WATERSHED, SÃO PAULO, BRAZIL}

\begin{abstract}
With the objective of verify the remainders influence of ciliary vegetation and of the human action on the water quality, four springs were studied, with two springs on presence of remaining natural vegetation and two springs with agricultural activities predominance. These springs are part of Córrego Rico watershed, being located in the municipal districts of Taquaritinga and Guariba, São Paulo State, Brazil, in two classes of soil: argisoil and latosoil, respectively. Points of collection of water were defined on the spring and along the water flow (among 0 to $50 \mathrm{~m}$ of the spring), in two periods (rainy and dry). The following variables were analyzed: color, $\mathrm{pH}$, temperature, turbidity, alkalinity, total hardness, magnesium hardness, calcium hardness, phosphorus, nitrogen and DBO. It was concluded that, in a general way, a separation for springs and also for periods was observed, confirming that the sampling periods as well as the characteristics and different uses of the soil influence the water quality of the watersheds. Color, turbidity, alkalinity, and total nitrogen are the variables that presented the better relative importance in the canonic variables.
\end{abstract}

KEYWORDS: small watersheds, water resources, land uses.

\footnotetext{
${ }^{1}$ Eng ${ }^{\text {a }}$ Agrônoma, Doutora em Agronomia (Produção Vegetal), UNESP, Jaboticabal - SP, Fone: (0XX16) 3209.2637, nicoledonadio@hotmail.com

${ }^{2}$ Eng $^{\circ}$ Agrônomo, Prof. Titular, Departamento de Engenharia Rural, UNESP, Jaboticabal - SP.

${ }^{3}$ Eng ${ }^{\circ}$ Florestal, Prof. Doutor, Departamento de Produção Vegetal, UNESP, Jaboticabal - SP.

Recebido pelo Conselho Editorial em: 13-11-2003

Aprovado pelo Conselho Editorial em: 8-3-2005
} 


\section{INTRODUÇÃO}

A água ocupa um lugar específico entre os recursos naturais. É a substância mais abundante no planeta, embora disponível em diferentes quantidades, em diferentes lugares. Possui papel fundamental no ambiente e na vida humana, e nada a substitui, pois sem ela a vida não pode existir.

Segundo TUNDISI (1999), alterações na quantidade, distribuição e qualidade dos recursos hídricos ameaçam a sobrevivência humana $\mathrm{e}$ as demais espécies do planeta, estando o desenvolvimento econômico e social dos países fundamentados na disponibilidade de água de boa qualidade e na capacidade de sua conservação e proteção.

No Brasil, embora a água seja considerada recurso abundante, existem áreas muito carentes a ponto de transformá-la em um bem limitado às necessidades do homem. Normalmente, a sua escassez é muito mais grave em regiões onde o desenvolvimento ocorreu de forma desordenada, provocando a deterioração das águas disponíveis, devido ao lançamento indiscriminado de esgotos domésticos, despejos industriais, agrotóxicos e outros poluentes (MOITA \& CUDO, 1991).

A qualidade da água de uma microbacia pode ser influenciada por diversos fatores e, dentre eles, estão o clima, a cobertura vegetal, a topografia, a geologia, bem como o tipo, o uso e o manejo do solo da bacia hidrográfica (VAZHEMIN, 1972; PEREIRA, 1997). Segundo ARCOVA et al. (1998), os vários processos que controlam a qualidade da água de determinado manancial fazem parte de um frágil equilíbrio, motivo pelo qual alterações de ordem física, química ou climática, na bacia hidrográfica, podem modificar a sua qualidade.

Nas bacias com cobertura de floresta natural, a vegetação promove a proteção contra a erosão do solo, a sedimentação e a lixiviação excessiva de nutrientes (SOPPER, 1975), sendo essas áreas muito importantes para manter o abastecimento de água de boa qualidade. Por outro lado, as práticas que se seguem após a retirada das árvores tendem a produzir intensa e prolongada degradação da qualidade da água (BROWN, 1988). Segundo o código florestal, em nascentes (mesmo intermitentes) e olhos d'água, a distância a ser preservada com mata é de $50 \mathrm{~m}$; no entanto, o que se observa muitas vezes é que as atividades agrícolas não respeitam essa distância.

Segundo OLIVEIRA-FILHO et al. (1994), a devastação das matas ciliares tem contribuído para o assoreamento, o aumento da turbidez das águas, o desequilíbrio do regime das cheias, a erosão das margens de grande número de cursos d'água, além do comprometimento da fauna silvestre. ARCOVA \& CICCO (1997) salientam que, nas microbacias de uso agrícola, quando comparadas às de uso florestal, o transporte de sedimentos e a perda de nutrientes são maiores. Para MARGALEF (1983), os sistemas aquáticos são receptores das descargas resultantes das várias atividades humanas nas bacias hidrográficas.

Como as áreas florestadas não perturbadas são a melhor condição desejada, do ponto de vista da proteção dos recursos hídricos, o monitoramento hidrológico das microbacias com vegetação natural remanescente serve como referência para a comparação com outras microbacias impactadas. Diversos estudos sobre a qualidade da água em microbacias têm sido realizados (PINEDA \& SCHAFER, 1987; ARCOVA \& CICCO, 1999; SOUZA \& TUNDISI, 2000; PRIMAVESI et al., 2002).

A adoção da bacia hidrográfica como unidade de planejamento é de aceitação internacional, não apenas porque ela representa uma unidade física bem caracterizada, tanto do ponto de vista de integração como da funcionalidade de seus elementos, mas também porque toda área de terra, por menor que seja, se integra a uma bacia (PISSARRA, 1998).

O uso de indicadores físico-químicos da qualidade da água consiste no emprego de variáveis que se correlacionam com as alterações ocorridas na microbacia, sejam essas de origem antrópica ou natural. 
O objetivo deste estudo foi verificar a influência da vegetação natural remanescente e de atividades agrícolas na qualidade da água de quatro nascentes, em dois tipos de solo da bacia hidrográfica do Córrego Rico.

\section{MATERIAL E MÉTODOS}

O estudo foi desenvolvido na bacia hidrográfica do Córrego Rico, com área aproximada de 1.221 ha, localizada na região Nordeste do Estado de São Paulo, região administrativa de Ribeirão Preto, compreendendo os municípios de Jaboticabal, Monte Alto, Taquaritinga, Santa Ernestina e Guariba. Essa bacia é integrante da Unidade de Gerenciamento de Recursos Hídricos do Rio Mogi Guaçu (UGRHI-9), no compartimento econômico-ecológico denominado Médio Mogi Inferior.

A classificação climática para a região, segundo Köeppen, é do tipo Cwa, ou seja, clima mesotérmico de inverno seco, em que a temperatura média do mês mais quente é superior a $22^{\circ} \mathrm{C}$ e a do mês mais frio inferior a $18{ }^{\circ} \mathrm{C}$. A precipitação média anual varia de $1.100 \mathrm{~mm}$ a $1.700 \mathrm{~mm}$. A média anual da umidade relativa do ar é de aproximadamente $71 \%$, ocorrendo concentração de chuvas no período de outubro a março e o período mais seco estende-se de abril até setembro.

As principais classes de solo encontradas na região são os Argissolos (Podzólicos) e os Latossolos, sendo que os Argissolos ocupam as cotas superiores, em um relevo mais acidentado, enquanto os Latossolos se encontram à medida que o relevo se suaviza (EMBRAPA, 1999). No município de Taquaritinga, predominam os Argissolos e em Guariba os Latossolos.

Avaliou-se a qualidade da água de quatro nascentes, sendo duas localizadas no município de Taquaritinga e duas em Guariba. Em cada município, foi estudada uma nascente com vegetação natural remanescente e uma com predomínio de agricultura.

As nascentes com vegetação natural remanescente possuem representantes arbóreos da Floresta Estacional Semidecidual e do Cerrado por estarem em uma região de transição entre essas formações.

No município de Taquaritinga, a nascente com vegetação natural remanescente está inserida em um fragmento florestal com área aproximada de 8 ha, sendo a área de preservação permanente maior que os $50 \mathrm{~m}$ previstos no código florestal e, ao entorno da vegetação natural remanescente, existe uma área de 200 m de pastagem formada seguida de cana-de-açúcar.

Em Guariba, o fragmento florestal onde está inserida a nascente com vegetação natural remanescente apresenta aproximadamente 5 ha, também com a faixa de vegetação natural dentro do exigido na legislação florestal e, ao seu redor, a cultura dominante é a cana-de-açúcar.

Nas nascentes com predomínio da agricultura, a cana-de-açúcar é a principal cultura e, em Taquaritinga, a cana está a aproximadamente $10 \mathrm{~m}$ da nascente e, em Guariba, a $20 \mathrm{~m}$. Nas duas áreas, a cana-de-açúcar é a cobertura vegetal predominante há mais de 10 anos.

Foram amostrados quatro pontos, em cada uma das nascentes estudadas, sendo um na nascente e os outros a 10 m, $30 \mathrm{~m}$ e $50 \mathrm{~m}$ da mesma na direção longitudinal. Foram definidos, também, alguns pontos na junção dos cursos d'água, conforme Tabela 1. Os pontos J N1-2 e J N3-4 são pontos de junção dos cursos d'água das nascentes 1 e 2, e 3 e 4, respectivamente. As nascentes denominadas 1 e 2 estão localizadas no município de Taquaritinga, e as denominadas 3 e 4 no município de Guariba.

As amostras de água foram coletadas entre maio e junho de 2002, sendo esse período considerado o período seco (P1) e entre fevereiro e março de 2003, considerado o período chuvoso, (P2). Para cada período, foram realizadas três coletas em cada um dos pontos amostrados, em três semanas consecutivas, sempre na parte da manhã e em dias sem chuva. A coleta, acondicionamento e conservação das amostras, assim como as análises, foram realizadas conforme métodos especificados 
em "Standard Methods for the Examination of Water and Wastewater", editado pela "American Public Health Association" (APHA, 1995).

TABELA 1. Localização dos pontos de coleta de água nas nascentes da bacia hidrográfica do Córrego Rico nos municípios de Taquaritinga e Guariba.

\begin{tabular}{llccc}
\hline \multicolumn{1}{c}{$\begin{array}{c}\text { Pontos de } \\
\text { Coleta }\end{array}$} & Usos do Solo & Distâncias das Nascentes & Municípios & Classes de Solo \\
\hline N1-Nascente & Vegetação natural & 0 m (na nascente) & Taquaritinga & Argissolo \\
N1-10 m & Vegetação natural & a $10 \mathrm{~m}$ da nascente & Taquaritinga & Argissolo \\
N1-30 m & Vegetação natural & a $30 \mathrm{~m}$ da nascente & Taquaritinga & Argissolo \\
N1-50 m & Vegetação natural & a $50 \mathrm{~m}$ da nascente & Taquaritinga & Argissolo \\
N2-Nascente & Agricultura & $0 \mathrm{~m}$ (na nascente) & Taquaritinga & Argissolo \\
N2-10 m & Agricultura & a $10 \mathrm{~m}$ da nascente & Taquaritinga & Argissolo \\
N2-30 m & Agricultura & a $30 \mathrm{~m}$ da nascente & Taquaritinga & Argissolo \\
N2-50 m & Agricultura & a $50 \mathrm{~m}$ da nascente & Taquaritinga & Argissolo \\
J N1-2 & Agricultura & Junção & Taquaritinga & Argissolo \\
N3-Nascente & Vegetação natural & 0 m (na nascente) & Guariba & Latossolo \\
N3-10 m & Vegetação natural & a $10 \mathrm{~m}$ da nascente & Guariba & Latossolo \\
N3-30 m & Vegetação natural & a $30 \mathrm{~m}$ da nascente & Guariba & Latossolo \\
N3-50 m & Vegetação natural & a $50 \mathrm{~m}$ da nascente & Guariba & Latossolo \\
N4-Nascente & Agricultura & $0 \mathrm{~m}$ (na nascente) & Guariba & Latossolo \\
N4-10 m & Agricultura & a $10 \mathrm{~m}$ da nascente & Guariba & Latossolo \\
N4-30 m & Agricultura & a $30 \mathrm{~m}$ da nascente & Guariba & Latossolo \\
N4-50 m & Agricultura & a $50 \mathrm{~m}$ da nascente & Guariba & Latossolo \\
J N3-4 & Agricultura & Junção & Guariba & Latossolo \\
\hline
\end{tabular}

Para a avaliação da qualidade da água, determinaram-se as variáveis físico-químicas, cor, pH, temperatura (Tpt.), turbidez (Turb.), alcalinidade (Alc.), dureza total (D. total), dureza em magnésio (D. $\mathrm{Mg}$ ), dureza em cálcio (D. Ca), fósforo $\left(\mathrm{PO}_{4}{ }^{-}\right)$, nitrogênio total ( $\mathrm{N}$ total) e demanda bioquímica de oxigênio (DBO). As análises foram feitas no laboratório de Análise de Água do Departamento de Engenharia Rural da Faculdade de Ciências Agrárias e Veterinárias, Câmpus de Jaboticabal (FCAV/UNESP).

$\mathrm{O}$ pH da água foi determinado por meio da leitura em potenciômetro digital. A temperatura da água foi determinada no próprio local de amostragem, por leitura direta em termômetro de mercúrio com escala interna. A cor, turbidez, dureza total, dureza em cálcio, dureza em magnésio, nitrogênio e fósforo foram determinados com uso do espectrofotômetro digital HACH DR 2000. A alcalinidade foi obtida por titulação com ácido sulfúrico $0,01 \mathrm{M}$. O valor da demanda bioquímica de oxigênio (DBO) foi obtido a partir da diferença inicial e final do oxigênio dissolvido (OD), mensurado em amostra no início e ao final de cinco dias de incubação, a $20^{\circ} \mathrm{C}$ (APHA, 1995).

Foram realizados estudos comparativos dos dados, aplicando-se a análise de agrupamento, utilizando-se do método de Tocher e da análise de correspondência canônica. Os dados de temperatura foram submetidos à transformação $10^{(4,3)}$ e os de turbidez, alcalinidade, dureza total, dureza em magnésio, dureza em cálcio, fosfato e nitrogênio total foram submetidos à transformação logarítmica. A DBO foi submetida à transformação 1/DBO. As variáveis cor e pH não necessitaram de transformação para serem analisadas. 
$\mathrm{Na}$ análise de agrupamento, as unidades operacionais foram os diferentes pontos de coleta de água e os dois períodos amostrados (18 estações x 2 períodos), os quais foram agrupados segundo as variáveis avaliadas.

A análise de variáveis canônicas foi utilizada na tentativa de reduzir o conjunto das variáveis num conjunto mais significativo, envolvendo menor número de variáveis. Essa análise cria variáveis denominadas variáveis canônicas (VC 1, VC 2, ..., VC(n)), que são combinações lineares das variáveis em estudo.

Para a identificação das caraterísticas de menor importância, descarta-se a variável de maior coeficiente de ponderação (em valor absoluto), a partir da última variável canônica e, quando a característica já foi descartada, prossegue-se a identificação na variável superior (CRUZ \& REGAZZI, 1994).

As análises de agrupamento e de variáveis canônicas foram realizadas no programa GENES (CRUZ, 2001).

\section{RESULTADOS E DISCUSSÃO}

Na Tabela 2, encontram-se os resultados dos valores médios originais das variáveis analisadas durante o período seco e chuvoso. De maneira geral, para as variáveis físico-químicas, as menores médias foram obtidas nos pontos de coleta das nascentes com vegetação natural remanescente, enquanto as maiores médias ocorreram nos pontos de coleta das nascentes com uso agrícola.

A temperatura variou de 17,5 a $19,8^{\circ} \mathrm{C}$ nos pontos amostrados nas nascentes 1 e 3 (com vegetação natural remanescente), refletindo condições semelhantes de sombreamento dos cursos de água proporcionados pela cobertura vegetal, e nos pontos das nascentes 2 e 4 (com agricultura), a temperatura variou de 20,2 a $22,6^{\circ} \mathrm{C}$. Para as quatro nascentes estudadas, nos dois períodos analisados, a temperatura aumentou sucessivamente à medida que os pontos de coleta se distanciavam das nascentes. Segundo SWIFT \& MESSER (1971) e SUGIMOTO et al. (1997), a manutenção da vegetação ciliar é a maneira mais efetiva de prevenir aumento da temperatura da água.

MATHEUS et al. (1995) citam que a maioria das espécies animais e vegetais têm exigências definidas quanto às temperaturas máximas e mínimas toleradas, sendo as variações de temperatura da água parte do regime climático natural, influenciando o metabolismo de comunidades aquáticas, como produtividade primária, respiração dos organismos e decomposição da matéria orgânica.

Em relação às comparações entre períodos seco e chuvoso, de maneira geral, as médias obtidas para o período seco foram inferiores às obtidas para o chuvoso, para as variáveis cor, fósforo, nitrogênio e DBO.

Para o $\mathrm{pH}$, os valores obtidos nos diferentes pontos de amostragem não variaram muito entre os períodos seco e chuvoso. A maioria dos valores estabilizaram-se entre 6,0 e 7,0, sendo semelhantes aos valores obtidos por AMARAL (1992), PALHARES et al. (2000) e BORGES (2001), que também estudaram as águas do Córrego Rico.

Segundo MATHEUS et al. (1995), a água no ambiente natural tem sua concentração de íons $\mathrm{H}^{+} \mathrm{e}$ $\mathrm{OH}^{-}$fortemente influenciada por sais, ácidos e bases presentes no meio, fornecendo assim informações sobre a sua qualidade (água pura valor igual a 7 e água superficial valor entre 4 e 9), o tipo de solo por onde a água percorreu, o tipo de poluição química da água (despejos ácidos ou alcalinos) e a qualidade do ambiente (origem da água, impactos ambientais poluidores, desmatamento e metabolismo das comunidades). 
TABELA 2. Valores médios das variáveis avaliadas nas nascentes dos municípios de Taquaritinga (N1 e N2) e Guariba (N3 e N4), nos diferentes pontos de coleta durante os períodos seco e chuvoso. US - usos do solo; V - vegetação natural; A - agricultura.

\begin{tabular}{|c|c|c|c|c|c|c|c|c|c|c|c|c|}
\hline \multirow{2}{*}{$\begin{array}{c}\text { Ponto } \\
\text { de Coleta }\end{array}$} & \multirow{2}{*}{ US } & \multirow{2}{*}{$\begin{array}{c}\text { Cor } \\
\left(m g L^{-1} \mathrm{Pt}\right)\end{array}$} & \multirow{2}{*}{$\mathrm{pH}$} & \multirow{2}{*}{$\begin{array}{l}\text { Tpt. } \\
\left({ }^{\circ} \mathrm{C}\right)\end{array}$} & \multirow{2}{*}{$\begin{array}{l}\text { Turb. } \\
\text { (UNT) }\end{array}$} & Alc. & D.total & D. $\mathrm{Mg}$ & D. $\mathrm{Ca}$ & $\mathrm{PO}_{4}^{-}$ & $\mathrm{N}$ total & DBO \\
\hline & & & & & & \multicolumn{7}{|c|}{$\left(\mathrm{mg} \mathrm{L}^{-1}\right)$} \\
\hline N1 Nascente P1 & $\mathrm{V}$ & 9 & 5,4 & 17,9 & 2,4 & 1,3 & 29,4 & 8,0 & 21,5 & 0,2 & 0,04 & 0,4 \\
\hline N1 10m P1 & $\mathrm{V}$ & 21 & 6,9 & 18,9 & 7,1 & 2,0 & 29,3 & 9,5 & 19,8 & 0,3 & 0,07 & 0,4 \\
\hline N1 30m P1 & $\mathrm{V}$ & 21 & 6,9 & 19,0 & 4,4 & 2,0 & 33,8 & 10,6 & 23,2 & 0,3 & 0,08 & 0,4 \\
\hline $\mathrm{N} 150 \mathrm{~m}$ P1 & $\mathrm{V}$ & 54 & 7,1 & 19,8 & 4,7 & 1,8 & 33,8 & 10,9 & 22,9 & 0,5 & 0,08 & 2,0 \\
\hline I $\mathrm{N} 2$ Nascente $\mathrm{P} 1$ & A & 117 & 6,1 & 20,3 & 13,7 & 0,8 & 24,0 & 6,7 & 17,3 & 1,3 & 0,27 & 0,3 \\
\hline$\Xi \quad \mathrm{N} 210 \mathrm{~m} \mathrm{P} 1$ & A & 147 & 6,0 & 20,5 & 12,2 & 1,4 & 15,1 & 4,2 & 10,9 & 1,4 & 0,35 & 0,3 \\
\hline $\mathrm{N} 230 \mathrm{~m}$ P1 & A & 131 & 6,8 & 20,5 & 23,5 & 1,6 & 23,1 & 7,9 & 15,2 & 2,0 & 0,32 & 0,4 \\
\hline $\mathrm{N} 250 \mathrm{~m} \mathrm{P} 1$ & A & 113 & 6,9 & 20,9 & 26,3 & 1,2 & 23,6 & 6,9 & 16,8 & 1,6 & 0,33 & 1,7 \\
\hline J N1-2 P1 & A & 70 & 6,7 & 21,5 & 8,9 & 2,0 & 38,8 & 22,4 & 16,4 & 0,5 & 0,16 & 0,4 \\
\hline D N3 Nascente P1 & $\mathrm{V}$ & 22 & 6,0 & 17,5 & 2,7 & 0,6 & 9,4 & 2,6 & 6,7 & 1,3 & 0,58 & 0,3 \\
\hline N3 10m P1 & $\mathrm{V}$ & 62 & 5,1 & 17,9 & 7,9 & 0,6 & 7,5 & 2,4 & 5,1 & 0,6 & 0,11 & 0,3 \\
\hline N3 30m P1 & $\mathrm{V}$ & 38 & 5,9 & 18,6 & 5,5 & 0,6 & 8,9 & 2,8 & 6,0 & 0,5 & 0,06 & 0,3 \\
\hline N3 50m P1 & $\mathrm{V}$ & 49 & 6,5 & 19,6 & 5,5 & 0,6 & 10,5 & 2,9 & 7,6 & 0,6 & 0,08 & 0,5 \\
\hline N4 Nascente P1 & A & 106 & 6,1 & 21,6 & 18,6 & 0,7 & 9,2 & 2,6 & 6,5 & 0,2 & 0,05 & 0,3 \\
\hline N4 10m P1 & A & 104 & 6,3 & 22,6 & 26,1 & 0,8 & 12,1 & 3,3 & 8,8 & 0,4 & 0,06 & 0,4 \\
\hline $\mathrm{N} 430 \mathrm{~m}$ P1 & A & 42 & 6,3 & 22,6 & 6,8 & 0,9 & 13,8 & 3,1 & 10,7 & 0,5 & 0,08 & 0,4 \\
\hline N4 50m P1 & A & 50 & 6,3 & 22,6 & 6,4 & 0,7 & 14,5 & 4,6 & 9,9 & 0,5 & 0,12 & 1,3 \\
\hline J N3-4 P1 & $\mathrm{A}$ & 45 & 6,7 & 20,0 & 7,9 & 0,7 & 12,9 & 3,9 & 9,0 & 0,5 & 0,13 & 1,7 \\
\hline N1 Nascente P2 & $\mathrm{V}$ & 14 & 5,5 & 17,8 & 5,1 & 1,3 & 24,9 & 7,2 & 17,7 & 0,7 & 0,07 & 0,7 \\
\hline $\mathrm{N} 110 \mathrm{~m}$ P2 & $\mathrm{V}$ & 82 & 6,7 & 18,7 & 13,2 & 1,2 & 26,2 & 7,9 & 18,3 & 2,6 & 0,26 & 0,6 \\
\hline N1 30m P2 & $\mathrm{V}$ & 88 & 6,9 & 19,1 & 14,7 & 1,0 & 29,9 & 8,8 & 21,0 & 2,1 & 0,16 & 0,7 \\
\hline $\mathrm{N} 150 \mathrm{~m}$ P2 & $\mathrm{V}$ & 99 & 7,2 & 19,7 & 15,9 & 0,9 & 33,7 & 10,3 & 23,5 & 2,7 & 0,22 & 0,7 \\
\hline N2 Nascente P2 & A & 200 & 6,0 & 20,2 & 27,1 & 0,8 & 14,2 & 3,6 & 10,6 & 3,9 & 0,38 & 0,6 \\
\hline $\mathrm{N} 210 \mathrm{mP}$ & A & 206 & 6,0 & 20,7 & 27,7 & 1,1 & 10,2 & 3,5 & 6,7 & 4,3 & 0,37 & 0,7 \\
\hline $\mathrm{N} 230 \mathrm{~m}$ P2 & A & 222 & 6,9 & 21,1 & 30,1 & 1,4 & 10,4 & 3,4 & 7,0 & 4,4 & 0,40 & 0,7 \\
\hline $\mathrm{N} 250 \mathrm{~m}$ P2 & A & 220 & 6,9 & 20,9 & 28,6 & 0,8 & 10,9 & 3,4 & 7,5 & 4,7 & 0,40 & 0,7 \\
\hline J N1-2 P2 & A & 87 & 6,6 & 21,2 & 4,7 & 1,4 & 38,4 & 14,8 & 23,6 & 0,9 & 0,25 & 0,7 \\
\hline V3 Nascente P2 & $\mathrm{V}$ & 31 & 6,2 & 17,9 & 4,5 & 0,5 & 3,7 & 0,7 & 3,0 & 1,2 & 0,31 & 0,7 \\
\hline N3 10m P2 & $\mathrm{V}$ & 39 & 5,9 & 18,2 & 5,0 & 0,5 & 4,2 & 0,8 & 3,4 & 0,9 & 0,10 & 0,8 \\
\hline N3 30m P2 & $\mathrm{V}$ & 48 & 6,2 & 18,4 & 3,8 & 0,6 & 5,8 & 1,2 & 4,6 & 0,7 & 0,08 & 0,7 \\
\hline N3 50m P2 & $\mathrm{V}$ & 48 & 6,4 & 19,0 & 3,4 & 0,4 & 5,6 & 1,4 & 4,2 & 1,0 & 0,12 & 0,7 \\
\hline N4 Nascente P2 & A & 95 & 6,4 & 21,1 & 14,9 & 0,4 & 6,7 & 1,6 & 5,1 & 0,7 & 0,10 & 0,8 \\
\hline $\mathrm{N} 410 \mathrm{~m}$ P2 & A & 85 & 6,3 & 21,6 & 13,5 & 0,7 & 6,2 & 1,7 & 4,5 & 0,5 & 0,05 & 0,7 \\
\hline $\mathrm{N} 430 \mathrm{~m}$ P2 & A & 42 & 6,3 & 21,8 & 6,1 & 0,5 & 6,6 & 1,9 & 4,7 & 0,4 & 0,39 & 0,7 \\
\hline $\mathrm{N} 450 \mathrm{~m}$ P2 & A & 51 & 6,3 & 22,4 & 5,8 & 0,5 & 6,3 & 1,8 & 4,4 & 0,4 & 0,36 & 0,7 \\
\hline J N3-4 P2 & $\mathrm{A}$ & 71 & 6,7 & 21,0 & 9,5 & 0,4 & 9,0 & 2,6 & 6,4 & 1,1 & 0,15 & 0,7 \\
\hline \multicolumn{2}{|l|}{ Valores F } & $5,5^{* *}$ & $8,5^{* *}$ & $16,5 * *$ & $4,9 * *$ & $7,9 * *$ & $37,9 * *$ & $56,3^{* *}$ & $18,6^{* *}$ & $10 * *$ & $3,2 * *$ & $0,9^{\mathrm{ns}}$ \\
\hline \multicolumn{2}{|l|}{ Média Geral } & 81,4 & 6,4 & 20,1 & 11,8 & 1 & 16,7 & 5,3 & 11,4 & 1,3 & 0,2 & 0,7 \\
\hline
\end{tabular}

Na Tabela 3, é apresentado o resultado da análise de agrupamento obtida entre os diferentes pontos de coleta da água, das quatro nascentes estudadas, nos dois períodos de estudo.

Foram identificados um total de 11 grupos; entre eles, os pontos de coletas localizados na origem das nascentes 2 (N2 Nascente P1) e 3 (N3 Nascente P1) e a dez metros da nascente 3 (N3 10 m P1), durante o período seco, mostraram-se diferentes dos demais, formando, assim, três grupos distintos e isolados (grupos 9; 10 e 11). 
TABELA 3. Formação dos grupos entre os diferentes pontos de coleta das quatro nascentes estudadas, durante os períodos seco e chuvoso.

\begin{tabular}{|c|c|c|c|c|c|c|c|c|}
\hline Grupo & & & & Ponto Am & strado & & & \\
\hline 1 & $\mathrm{~N} 110 \mathrm{~m} \mathrm{P} 1$ & $\mathrm{~N} 130 \mathrm{~m} \mathrm{P} 1$ & $\mathrm{~N} 150 \mathrm{~m} \mathrm{P} 1$ & $\mathrm{~N} 230 \mathrm{~m} \mathrm{P} 1$ & $\mathrm{~N} 250 \mathrm{~m} \mathrm{P} 1$ & $\mathrm{~N} 110 \mathrm{~m} \mathrm{P} 2$ & $\mathrm{~N} 130 \mathrm{~m}$ P2 & $\mathrm{N} 150 \mathrm{~m} \mathrm{P} 2$ \\
\hline 2 & N3 Nascente P2 & $\mathrm{N} 310 \mathrm{~m} \mathrm{P} 2$ & $\mathrm{~N} 330 \mathrm{~m}$ P2 & $\mathrm{N} 350 \mathrm{~m} \mathrm{P} 2$ & & & & \\
\hline 3 & N4 Nascente P1 & $\mathrm{N} 410 \mathrm{~m} \mathrm{P} 1$ & $\mathrm{~N} 430 \mathrm{~m}$ P1 & $\mathrm{N} 450 \mathrm{~m} \mathrm{P} 1$ & & & & \\
\hline 4 & N4 Nascente P2 & $\mathrm{N} 410 \mathrm{~m} \mathrm{P} 2$ & $\mathrm{~N} 430 \mathrm{~m}$ P2 & $\mathrm{N} 450 \mathrm{~m} \mathrm{P} 2$ & J N3-4 P2 & & & \\
\hline 5 & N2 Nascente P2 & $\mathrm{N} 210 \mathrm{~m} \mathrm{P} 2$ & $\mathrm{~N} 230 \mathrm{~m} \mathrm{P} 2$ & $\mathrm{~N} 250 \mathrm{~m} \mathrm{P} 2$ & $\mathrm{~N} 210 \mathrm{~m} \mathrm{P} 1$ & & & \\
\hline 6 & $\mathrm{~N} 330 \mathrm{~m}$ P1 & $\mathrm{N} 350 \mathrm{~m} \mathrm{P} 1$ & J N3-4 P1 & & & & & \\
\hline 7 & N1 Nascente P1 & N1 Nascente P2 & & & & & & \\
\hline 8 & J N1-2 P1 & J N1-2 P2 & & & & & & \\
\hline 9 & N2 Nascente P1 & & & & & & & \\
\hline 10 & N3 Nascente P1 & & & & & & & \\
\hline 11 & N3 10 m P1 & & & & & & & \\
\hline
\end{tabular}

De maneira geral, ocorreu a separação por nascente e por período, confirmando que os períodos de amostragem, assim como as características e os diferentes usos do solo, influenciam na qualidade da água das microbacias.

$\mathrm{Na}$ análise de correspondência canônica, as duas primeiras variáveis explicam 80,83\% da variância total, com a primeira variável canônica (VC1) explicando 55,42\% e a segunda (VC2) explicando 25,41\% da variabilidade dos dados (Tabela 4). Nesse tipo de análise estatística, é necessário que as duas primeiras variáveis expliquem mais que $50 \%$ da variância total para que a análise possa ser considerada significativa.

TABELA 4. Coeficientes de ponderação das variáveis originais, no estabelecimento das duas primeiras variáveis canônicas (VC1 e VC2).

\begin{tabular}{lcc}
\hline Variáveis Originais & Variável Canônica 1 (VC 1) & Variável Canônica 2 (VC 2) \\
\hline Cor & 0,00583 & 0,01249 \\
pH & 0,52733 & 1,58273 \\
Temperatura & $-0,01168$ & 0,10113 \\
Turbidez & 0,04581 & $-0,72354$ \\
Alcalinidade & 3,24204 & 1,15471 \\
Dureza total & 2,02939 & $-5,42090$ \\
Dureza em Mg & 11,33255 & 2,58379 \\
Dureza em Ca & 0,10319 & 0,19957 \\
Fósforo & $-0,98894$ & $-2,72964$ \\
Nitrogênio total & 0,13141 & $-0,08341$ \\
DBO & $-0,29852$ & 0,43299 \\
\hline Porcentagem de variação & 55,42 & 25,41 \\
Porcentagem de variação total & & 80,83 \\
\hline
\end{tabular}

Na Figura 1, ilustra-se a distribuição dos pontos amostrados no conjunto dos dois períodos estudados. A dispersão dos escores das duas primeiras variáveis canônicas conduzem à formação de grupos semelhantes aos obtidos na análise de agrupamento; contudo, nessa figura, alguns pontos que apareceram isolados na análise de agrupamento (Tabela 3) foram melhor agrupados. Como exemplos, estão os pontos localizados a 0 e $10 \mathrm{~m}$ da nascente 3 (pontos 17 e 19), que na análise de agrupamento apareceram isolados, formando os grupos 10 (N3 Nascente P1) e 11 (N3 $10 \mathrm{~m} \mathrm{P1),} \mathrm{e} \mathrm{que,} \mathrm{na} \mathrm{Figura} \mathrm{1,}$ poderiam ser agrupados com os pontos 21 (N3 $30 \mathrm{~m} \mathrm{P} 1)$ e 23 ( N3 $5 \mathrm{~m} \mathrm{P} 1)$, pontos que pertenciam ao grupo 6 na análise de agrupamento. 
Conforme Figura 1, os pontos localizados na nascente 1, obtidos durante o período seco $(1 ; 3 ; 5$ e 7) e chuvoso (2; 4; 6 e 8), estão localizados na extremidade positiva do eixo da variável canônica 1 (VC1), podendo formar um único grupo. Essa tendência já foi observada no grupo 1 obtido pela análise de agrupamento (Tabela 3).

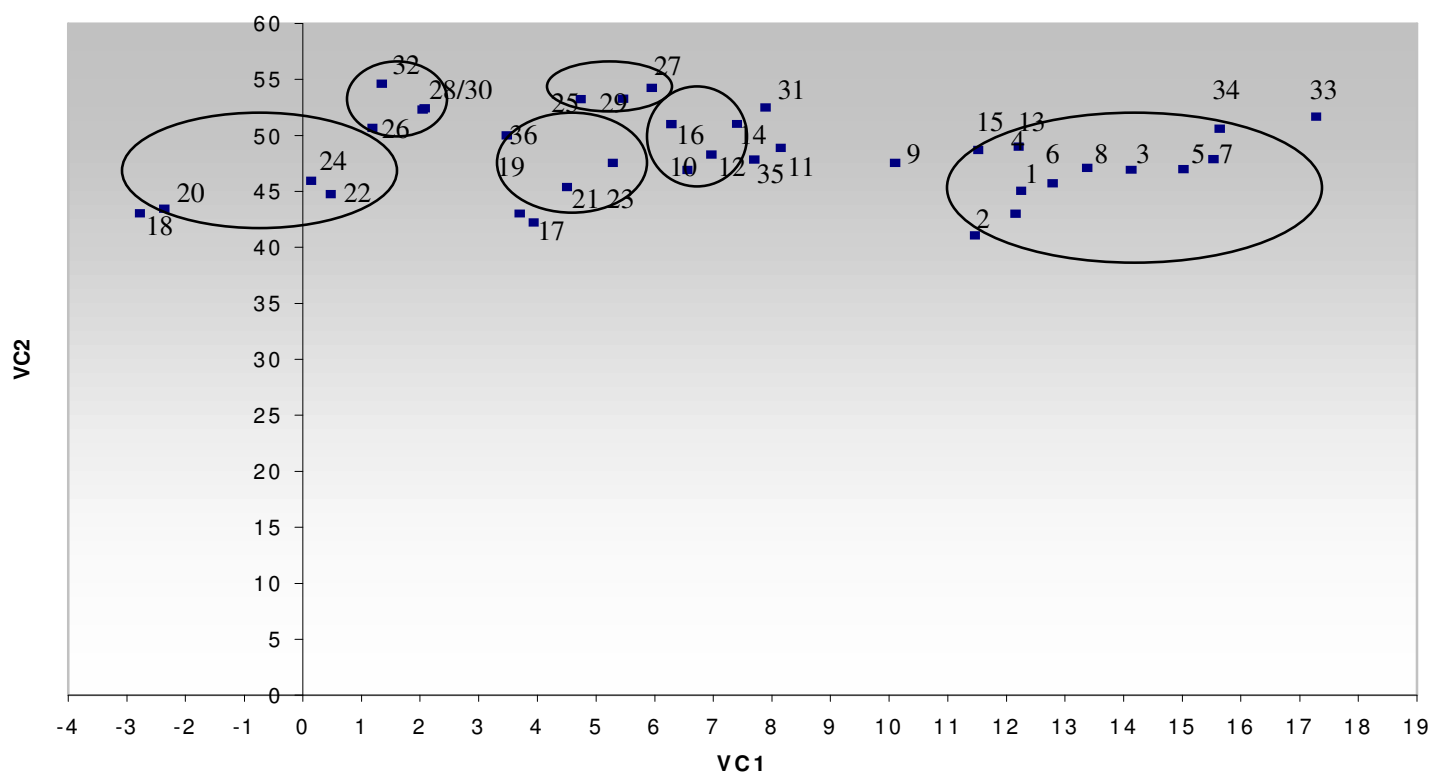

FIGURA 1. Dispersão dos pontos de coleta de água (escores canônicos), no espaço, de acordo com as duas primeiras variáveis canônicas, nos dois períodos amostrados. $(1=\mathrm{N} 1$ Nascente $\mathrm{P} 1$; $2=\mathrm{N} 1$ Nascente P2; $3=\mathrm{N} 110 \mathrm{~m} \mathrm{P} 1 ; 4=\mathrm{N} 110 \mathrm{~m}$ P2; $5=\mathrm{N} 130 \mathrm{~m} \mathrm{P} 1 ; 6=\mathrm{N} 130 \mathrm{~m} \mathrm{P} 2$; $7=\mathrm{N} 150 \mathrm{~m} \mathrm{P} 1 ; 8=\mathrm{N} 150 \mathrm{~m} \mathrm{P} 2 ; 9=\mathrm{N} 2$ Nascente P1; $10=\mathrm{N} 2$ Nascente P2;11 = N2 $10 \mathrm{~m} \mathrm{P} 1 ; 12=\mathrm{N} 210 \mathrm{~m} \mathrm{P} 2 ; 13=\mathrm{N} 230 \mathrm{~m} \mathrm{P} 1 ; 14=\mathrm{N} 230 \mathrm{~m} \mathrm{P} 2 ; 15=\mathrm{N} 250 \mathrm{~m} \mathrm{P} 1 ;$ $16=\mathrm{N} 250 \mathrm{~m} \mathrm{P} 2 ; 17=\mathrm{N} 3$ Nascente $\mathrm{P} 1 ; 18=\mathrm{N} 3$ Nascente P2;19=N3 $10 \mathrm{~m} \mathrm{P} 1 ; 20=\mathrm{N} 3$ $10 \mathrm{~m} \mathrm{P} 2 ; 21=\mathrm{N} 330 \mathrm{~m} \mathrm{P} 1 ; 22=\mathrm{N} 330 \mathrm{~m} \mathrm{P} 2 ; 23=\mathrm{N} 350 \mathrm{~m} \mathrm{P} 1 ; 24=\mathrm{N} 350 \mathrm{~m} \mathrm{P} 2$; $25=\mathrm{N} 4$ Nascente P1; $26=\mathrm{N} 4$ Nascente P2; $27=\mathrm{N} 410 \mathrm{~m} \mathrm{P} 1 ; 28=\mathrm{N} 410 \mathrm{~m} \mathrm{P} 2 ; 29=\mathrm{N} 4$ $30 \mathrm{~m} \mathrm{P} 1 ; 30=\mathrm{N} 430 \mathrm{~m} \mathrm{P} 2 ; 31=\mathrm{N} 450 \mathrm{~m} \mathrm{P} 1 ; 32=\mathrm{N} 450 \mathrm{~m} \mathrm{P} 2 ; 33=\mathrm{JN} 1-2 \mathrm{P} 1$; $34=\mathrm{JN} 1-2 \mathrm{P} 2 ; 35=\mathrm{JN} 3-4 \mathrm{P} 1 ; 36=\mathrm{JN} 3-4 \mathrm{P} 2)$.

Para os pontos da nascente 2, a dispersão mostra que os pontos obtidos durante o período seco (9; $11 ; 13$ e 15) se encontraram mais dispersos que os obtidos durante o período chuvoso (10; $12 ; 14$ e 16), podendo formar dois grupos distintos. Os pontos da nascente 3 (Figura 1) apresentaram melhor agrupamento de pontos obtidos durante o período seco $(17 ; 19 ; 21$ e 23$)$ e chuvoso (18; 20; 22 e 24).

$\mathrm{Na}$ nascente 4 , os pontos obtidos durante o período seco $(25 ; 27 ; 29$ e 31$)$ separaram-se dos obtidos durante o período chuvoso $(26 ; 28 ; 30$ e 32$)$, conforme também ocorreu na análise de agrupamento. Assim, a análise de agrupamento e a dispersão dos pontos de coleta de água, de acordo com as duas primeiras variáveis canônicas, completam-se.

Na Tabela 5, é apresentada a importância relativa das características estudadas nas variáveis canônicas. A dureza total foi a variável que apresentou menor importância relativa, seguida pela DBO, dureza em cálcio, $\mathrm{pH}$, fósforo, temperatura e dureza em magnésio. A cor, turbidez, alcalinidade e nitrogênio total foram as variáveis de maior importância relativa nas variáveis canônicas.

A baixa importância relativa apresentada pela dureza total deve-se, principalmente, ao fato de ela estar altamente correlacionada com a dureza em magnésio. 
TABELA 5. Importância relativa das características estudadas nas variáveis canônicas.

\begin{tabular}{crrrrrrrrrrr}
\hline Variáveis & \multicolumn{10}{c}{ Características Estudadas } \\
Canônicas & \multicolumn{1}{c}{ Cor } & \multicolumn{1}{c}{ pH } & \multicolumn{1}{c}{ Tpt. } & \multicolumn{1}{c}{ Turb. } & \multicolumn{1}{c}{ Alc. } & D.total & D. Mg & D. Ca & \multicolumn{1}{c}{ PO $_{4}^{-}$} & N total & \multicolumn{1}{c}{ DBO } \\
\hline VC 1 & 0,2501 & 0,1525 & $-0,1526$ & 0,0110 & 0,4127 & 0,1704 & 0,9215 & 0,0265 & $-0,1911$ & 0,0442 & $-0,4548$ \\
VC 2 & 0,5358 & 0,4577 & 1,3216 & $-0,1751$ & 0,1470 & $-0,4553$ & 0,2101 & 0,0513 & $-0,5276$ & $-0,0280$ & 0,6598 \\
VC 3 & $-0,3064$ & 0,3296 & 0,0548 & $-0,0831$ & 0,0591 & $-0,3872$ & 0,1467 & 0,2185 & 1,0821 & 0,0719 & 0,1728 \\
VC 4 & $-0,6760$ & 0,8141 & 0,0547 & $-0,3439$ & $-0,2696$ & 0,0224 & $-0,2016$ & 0,3126 & 0,1966 & $-0,1890$ & 0,4071 \\
VC 5 & 0,1736 & 0,4056 & $-0,3397$ & 0,5267 & 0,7155 & 1,0889 & $-0,5469$ & $-1,2156$ & $-0,4930$ & 0,0389 & $-0,3312$ \\
VC 6 & $-0,2499$ & $-0,0844$ & 0,1009 & $-0,4632$ & 0,4808 & 0,8375 & $-0,1698$ & $-1,1453$ & $-0,0331$ & 0,7511 & 0,0801 \\
VC 7 & $-0,3176$ & $-0,0552$ & 0,0375 & 0,2669 & 0,1081 & $-0,8958$ & $-0,0790$ & 1,4076 & $-0,1559$ & 0,6106 & $-0,1001$ \\
VC 8 & 0,1977 & $-0,1100$ & 0,1657 & $-0,5319$ & 0,4238 & $-0,4006$ & $-0,0924$ & 0,5604 & 0,2552 & $-0,4215$ & 0,7930 \\
VC 9 & $-0,5503$ & 0,0555 & $-0,0769$ & 0,4434 & 0,0340 & $-3,0122$ & 1,2844 & 2,0954 & 0,0263 & 0,1341 & 0,3290 \\
VC 10 & $-0,9650$ & $-0,0791$ & 0,0703 & 0,6680 & 0,1175 & $1,4216-0,5816$ & $-1,0503$ & 0,3508 & $-0,0808$ & 0,6504 \\
VC 11 & 0,5624 & $0,1419-0,2036$ & $-0,0114$ & $-0,2413$ & $0,6079-0,2513$ & $-0,3527$ & $-0,4914$ & 0,3708 & 0,3119 \\
\hline
\end{tabular}

A DBO apresentou baixa importância relativa, por apresentar baixo valor de $\mathrm{F}$ e por ser uma variável com pouca variação em seus valores médios. A dureza em cálcio, por sua vez, apresentou alta correlação com a alcalinidade e com a dureza em magnésio, podendo explicar sua baixa importância. A baixa importância relativa apresentada pelo $\mathrm{pH}$ pode ser explicada pela pouca variação de seus valores médios. O fósforo apresentou alta correlação com nitrogênio total, e a temperatura apresentou pouca variação. A dureza em magnésio apresentou alta correlação com a alcalinidade, permitindo que essa variável representasse a dureza total e a dureza em cálcio.

PRIMAVESI et al. (2002) utilizaram a análise multivariada para avaliar a qualidade da água na microbacia hidrográfica do Ribeirão do Canchim, em São Carlos - SP, e observaram que o pH, a alcalinidade e a dureza total se correlacionaram.

ARCOVA \& CICCO (1999), estudando a qualidade da água de microbacias com diferentes usos do solo, na região de Cunha, verificaram que os valores da temperatura, turbidez e cor aparente da água nas microbacias com agricultura foram superiores aos registrados nas microbacias florestadas, o que também foi observado neste estudo.

A CETESB (1995) considera que o aumento da temperatura intensifica a produção fitoplanctônica, aumenta a absorção de nutrientes por esses organismos, diminui a solubilidade do oxigênio na água, aumenta a solubilidade de vários compostos químicos e aumenta o efeito deletério dos poluentes sobre a vida aquática.

$\mathrm{O} \mathrm{N}_{\text {total }}$ demonstra a contribuição total de nutrientes em água e o nível de eutrofização da mesma. O nitrogênio é um elemento do metabolismo de ecossistemas aquáticos, contribuindo para a formação das proteínas e podendo atuar como fator limitante na produção primária. Do ponto de vista sanitário, esse elemento, ao ser incorporado a qualquer água, aumenta a proliferação de microrganismos, podendo aumentar a DBO do sistema (PALMA-SILVA, 1999).

Segundo SILVA \& PRUSKI (1997), o papel do fósforo na eutrofização dos recursos hídricos é essencial, e a origem desse nutriente a partir de áreas agrícolas tem sido colocada em relevância como indicador de qualidade de água, já que outros indicadores, como sólidos em suspensão e turbidez, estão associados ao transporte de fósforo. Nesse trabalho, ficou evidente a influência da concentração de $\mathrm{PO}_{4}{ }^{-}$na deterioração da qualidade da água, sendo o uso agrícola o principal causador.

NETO et al. (1993) encontraram diferenças mineralógicas em rios tributários do Rio MansoCuiabá devido a diferenças geológicas e ao tipo de solo das microbacias hidrográficas. 
SOUZA \& TUNDISI (2000), estudando variáveis hidrogeoquímicas das bacias hidrográficas dos rios Jaú e Jacaré-Guaçu - SP, concluíram que essas variáveis sofrem influência da ação antrópica, do substrato geológico e do tipo de solo.

PRIMAVESI et al. (2002), avaliando a qualidade da água em áreas com diferentes usos do solo, verificaram que, na nascente com mata, a qualidade da água se mostrou melhor que nas nascentes com uso agrícola, sendo a cor, dureza, turbidez, condutividade elétrica, alcalinidade, $\mathrm{pH}$, demanda química de oxigênio (DQO) e oxigênio dissolvido (OD) as variáveis que mais explicaram essas diferenças.

\section{CONCLUSÕES}

A presença de remanescentes de vegetação ciliar auxiliam na proteção dos recursos hídricos.

Os períodos de amostragem, assim como as características do solo e seus diferentes usos, influenciam na qualidade da água das microbacias.

Nas nascentes com vegetação natural remanescente, a qualidade da água mostrou-se melhor que nas nascentes com uso agrícola, sendo as variáveis cor, turbidez, alcalinidade e nitrogênio total as que mais explicaram essas diferenças.

\section{REFERÊNCIAS}

AMARAL, L.A. do. Influência da precipitação pluviométrica nas características bacteriológicas, físicas e químicas da água de diferentes mananciais de abastecimento da cidade de Jaboticabal - SP. 1992. 107 f. Tese (Doutorado em Saúde Ambiental) - Faculdade de Saúde Pública, Universidade de São Paulo, São Paulo, 1992.

APHA - American Public Health Association. Standard methods for examination of water and wastewater. $19^{\text {th }}$ ed. Washington: EPS Group, 1995. 1.268 p.

ARCOVA, F.C.S.; CESAR, S.F.; CICCO, V. Qualidade da água em microbacias recobertas por floresta de Mata Atlântica, Cunha, São Paulo. Revista do Instituto Florestal de São Paulo, São Paulo, v.10, n.2, p.185-96, 1998.

ARCOVA, F.C.S.; CICCO, V. Características do deflúvio de duas microbacias hidrográficas no laboratório de hidrologia florestal Walter Emmench, Cunha - SP. Revista do Instituto Florestal de São Paulo, São Paulo, v.9, n.2, p.153-70, 1997.

ARCOVA, F.C.S.; CICCO, V. Qualidade da água de microbacias com diferentes usos do solo na região de Cunha, Estado de São Paulo. Scientia Forestalis, Piracicaba, v.5, n.6, p.125-34, 1999.

BORGES, M. J. Avaliação de parâmetros de qualidade de solo e da água em áreas dos córregos Cerradinho e Jaboticabal, como subsídio para o planejamento ambiental. 2001. 114 f. Dissertação (Mestrado Conservação e Manejo de Recursos) - Centro de Estudos Ambientais, Universidade Estadual Paulista, Rio Claro, 2001.

BROWN, G.W. Forestry and water quality. $2^{\text {nd }}$ ed. Oregon: [s.n.], 1988. 142 p.

CETESB. Relatório de qualidade de água interiores do Estado de São Paulo 1995. São Paulo: Cetesb, 1995. 286 p. (Série Relatórios)

CRUZ, C.D. Programa Genes: Versão Windows - aplicativo computacional em genética e estatística. Viçosa: UFV, 2001. 648 p.

EMPRESA BRASILEIRA DE PESQUISA AGROPECUÁRIA. Centro Nacional de Pesquisa de Solos. Sistema brasileiro de classificação de solos. Rio de Janeiro, 1999. 412 p.

MARGALEF, R. Limnologia. Barcelona: Omega, 1983. 100 p. 
MOITA, R.; CUDO, K. Aspectos gerais da qualidade da água no Brasil. In: REUNIÃO TÉCNICA SOBRE QUALIDADE DA ÁGUA PARA CONSUMO HUMANO E SAÚDE NO BRASIL, 1991, Brasília. Anais... Brasília: Ministério da Saúde, Secretaria do Meio Ambiente, 1991. p.1-6.

NETO, M.S.S.; ALVEZ, R.; FIGUEIREDO, A.C.; HINO, K. Caracterização hidrogeoquímica da bacia do rio Manso-Cuiabá, Mato Grosso. Acta Limnológica Brasiliensia, São Carlos, v.6, p.230-44, 1993.

OLIVEIRA-FILHO, A.T.; ALMEIDA, R.J. de; MELLO, J.M. de; GAVILANES, M.L. Estrutura fitossociológica e variáveis ambientais em um trecho de mata ciliar do córrego Vilas Boas, Reserva Biológica do Poço Bonito, Lavras (MG). Revista Brasileira de Botânica, São Paulo, v.17, n.1, p.67-85, 1994.

PALHARES, J.C.P.; SCANDOLERA, A.J.; LUCAS JR., J.; COSTA, A.J. da. Monitoramento da qualidade da água do Córrego Jaboticabal através de parâmetros químicos. In: WORKSHOP DE INTEGRAÇÃO DE INFORMAÇÃO DA BACIA HIDROGRÁFICA DO RIO MOGI GUAÇU, 3., 2000, Porto Ferreira. Anais... Porto Ferreira: Prefeitura Municipal de Porto Ferreira, 2000. p.43-4.

PALMA-SILVA, G. M. Diagnóstico ambiental, qualidade da água e índice de depuração do Rio Corumbataí - SP. 1999. 155 f. Dissertação (Mestrado em Manejo Integrado de Recursos) - Centro de Estudos Ambientais, Universidade Estadual Paulista, Rio Claro, 1999.

PEREIRA, V.P. Solo: manejo e controle de erosão hídrica. Jaboticabal: FCAV, 1997. 56 p.

PINEDA, M.D.; SCHAFER, A. Adequação de critérios e métodos de avaliação da qualidade de águas superficiais baseada no estudo ecológico do rio Gravataí, Rio Grande do Sul, Brasil. Ciência e Cultura, São Paulo, v.39, n.2, p.198-206, 1987.

PISSARRA, T.C.T. Avaliação quantitativa das características geomórficas de microbacias hidrográficas de $1^{\underline{a}}$ ordem de magnitude em quatro posições do sistema de drenagem. 1998. $124 \mathrm{f}$. Dissertação (Mestrado em Produção Vegetal) - Faculdade de Ciências Agrárias e Veterinárias, Universidade Estadual Paulista, Jaboticabal, 1998.

PRIMAVESI, O.; FREITAS, A.R. de; PRIMAVESI, A.C.; OLIVEIRA, H.T. de. Water quality of Canchim's creek watershed in São Paulo, SP, Brazil, occupied by beef and dairy cattle activities. Brazilian Archives of Biology and Technology, Curitiba, v.45, n.2, p.209-17, 2002.

SILVA, D.D.; PRUSKI, F.F. Recursos hídricos e desenvolvimento sustentável da agricultura. Brasília: MMA; SRH; ABEAS; Viçosa, MG: UFV, 1997. 252 p.

SOPPER, W. E. Effects of timber harvesting and related management practices on water quality in forested watersheds. Journal of Environmental Quality, Madison, v.4, n.1, p.24-9, 1975.

SOUZA, A.D.G. de; TUNDISI, J.G. Hidrogeochemical comparative study of the Jaú and JacaréGuaçu river watersheds, São Paulo, Brazil. Revista Brasileira de Biologia, Rio de Janeiro, v.60, n.4, p.563-70, 2000.

SUGIMOTO, S.; NAKAMURA, F.; ITO. A. Heat budget and statistical analysis of the relationship between stream temperature and riparian forest in the Toikanbetsu river basin, Northern Japan. Journal of Forest Research, Ottawa, v.2, n.2, p.103-7, 1997.

SWIFT JR., L.M.; MESSER, J.B. Forest cuttings raise temperatures of small streams in the southern Appalachians. Journal of Soil and Water Conservation, Ankeny, v.26, n.23, p.111-17, 1971.

TUNDISI, J.G. Limnologia do século XXI: perspectivas e desafios. São Carlos: Suprema Gráfica e Editora, IIE, 1999. 24 p.

VAZHEMIN, I.G. Chemical composition of natural waters in the VYG river basin in relation to the soil of Central Karelia. Soviet Soil Science, Silver Spring, v.4, n.1, p.90-101, 1972. 